\section{Bacurau: uma situação colonial?}

\section{Bacurau: a colonial situation?}

\section{Rafael Ferreira Passos}

Universidade Federal do Rio Grande do Norte. Centro de Ciências Humanas, Letras

e Artes.

\section{RESUMO:}

A produção cinematográfica brasileira - e o pensamento teórico/crítico gestado por tal - apresenta, de maneira recorrente, influxos acerca do problema do subdesenvolvimento. O movimento do Cinema Novo é simbólico nesse sentido por tentar incorporar criativamente a própria precariedade econômica e técnica, índices do terceiro mundo, na linguagem cinematográfica de seus filmes, buscando uma dicção original, isto é, independente dos repertórios estrangeiros. Outras manifestações artísticas também irão pôr em perspectiva a construção da identidade nacional em diálogo com o discurso da precariedade (como o

\section{ABSTRACT:}

The Brazilian cinematographic production - and the theoretical / critical thinking started by it - presents, in recurring way, influxes about the problem of underdevelopment. Cinema Novo's movement is symbolic in this sense for trying to creatively incorporate its own economic and technical precariousness, third world indices, into the cinematographic language of its films, seeking an original diction, that is, independent of foreign repertoires. Other artistic manifestations will also put in perspective the construction of national identity in dialogue with the precariousness discourse (such as tropicalism in music and marginal tropicalismo na música e o cinema marginal, por exemplo), e é nessa toada que este artigo pretende analisar o filme Bacurau (2019), dirigido pelos cineastas pernambucanos Kleber Mendonça Filho e Juliano Dornelles. Para tal, recorremos sobretudo ao estudo da violência como produto de uma estética derivada da Estética da fome, manifesto escrito por Glauber Rocha para definir a ética e a estética do cinema produzido em terras tupiniquins. Além disso, buscamos mapearhistoricamenteolonganocampo da contemporaneidade, identificando elementos por vezes anacrônicos acoplados a tessitura cinematográfica do filme. Debruçamo-nos, pois, tanto a investigação dos aspectos próprios da linguagem fílmica (enquadramentos, diálogos, movimentos de câmera etc.), quanto à interação desses elementos com estudos ligados ao campo da história e da sociologia, de modo a tornar a leitura dinâmica, dialética, no sentido de discutir arte e sociedade. cinema, for example), and it is in this tone that this article intends to analyze the film Bacurau (2019), directed by Pernambuco's filmmakers Kleber Mendonça Filho and Juliano Dornelles. To this end, we resort mainly to the study of violence as a product of an aesthetic derived from the Aesthetics of Hunger (Estética da fome), a manifesto by Glauber Rocha to define the ethics and aesthetics of cinema produced in tupiniquins's lands. In addition, we seek to map historically the film in the field of contemporaneity, identifying elements that are sometimes anachronistic together with the cinematographic tissue of the film. Therefore, we looked at the investigation of the proper aspects of film language (framing, dialogues, camera movements, etc.), as well as the interaction of these elements with studies related to the fields of history and sociology, in order to make dynamic the reading, dialectic, in the sense of discussing art and society. 


\section{P A L A V R A S - C H A V E : KEYWORDS: Underdevelopment}

Subdesenvolvimento; Cinema Novo; Cinema Novo; Bacurau; Violence;

Bacurau; Violência; Contemporaneidade Contemporaneity.
Não somos europeus nem americanos do

Norte, mas, destituídos de cultura original, nada nos é estrangeiro, pois tudo o é. A penosa construção de nós mesmos se desenvolve na dialética rarefeita entre o não ser e o ser outro. (EMÍLIO, Paulo. In:

\section{Uma situação colonial?. 2016)}

\section{Introdução}

Asentençadocélebrecríticoehistoriador paulista que antecede este texto nos leva a pensar em como se dá a construção de nós mesmos enquanto brasileiros, isto é, quais são os acervos de imagens e de discursos que nos constituem? Paulo Emílio analisa em seus artigos e ensaios a produção cinematográfica brasileira a partir do índice da colonização, do subdesenvolvimento, de nossa dependência cultural em relação aos repertórios não-brasileiros. Em texto produzido para a primeira Convenção Nacional da Crítica Cinematográfica intitulado Uma situação colonial?, o crítico argumenta que:
O denominador comum de todas as atividades relacionadas com o cinema é em nosso país a mediocridade. A indústria,

as cinematecas, o comércio, os clubes de cinema, os laboratórios, a crítica, a legislação, os quadros técnicos e artísticos, o público e tudo o mais que se relacione com o cinema no Brasil apresentam a marca cruel do subdesenvolvimento (EMÍLIO, 2016, p. 47-48)

A constituição cultural tupiniquim se dá no interregno entre o vazio nosso representado simbolicamente, inclusive, pela inexistência de uma indústria cultural sólida, dado importante quando refletimos o cinema, arte industrial por excelência - e as enunciações do outro. No ínterim entre a data de publicação do artigo (meados de 1960) do autor de $O$ cinema no século e os dias atuais (meados de 2020), acreditamos que as artes brasileiras passaram por algumas convulsões que tensionaram os seus modelos de representação, tais quais: o Cinema Novo, marcado sobretudo pela figura totêmica de Glauber 
Rocha; o cinema marginal de Rogério Sganzerla, Júlio Bressane, Jairo Ferreira e companhia; o tropicalismo de Tom Zé, Gilberto Gil e Caetano Veloso; o museumundo de Hélio Oiticica; a poesia concreta do grupo paulista formado por Décio Pignatari e os irmãos Augusto e Haroldo de Campos; o neoconcretismo de Ferreira Gullar; o mangue eletrônico de Chico Science e a Nação Zumbi etc. No caso específico do cinema feito desde os anos 2000, passamos por dois períodos importantes: a retomada e a pós-retomada.

Esses movimentos estabeleceram, a partir de suas particularidades estéticas, maneiras de dizer, de sentir, de ver e de viver o Brasil e o brasileiro, gerando uma teia rizomática de imaginários acerca do país que se repetem no percurso da história. Essas repetições encadeiam uma série de enunciados que nos constituem: a colonização, o subdesenvolvimento, a precariedade, por exemplo, são alguns deles. Este trabalho pretende, portanto, visitando alguns destes acervos de imagens e de discursos, realizar uma leitura intra e extraestética (de modo que nos valeremos das camadas especificas da linguagem fílmica, bem como das interpretações sociais para as quais a obra aponta ou sugere) do filme Bacurau (2019), tendo em vista sobretudo o problema da violência como força de resistência ou força revolucionária na dissolução de entraves relacionados a uma região ou espaço, tensão que faz partedateleologiada obra.Pretendemos, ainda, situar o filme no terreno do cinema contemporâneo brasileiro e, para tal, discutiremos o gênero nordestern - termo cunhado pelo pesquisador Salvyano Cavalcanti para designar filmes nordestinos influenciados pelos westerns estadunidenses cujas temáticas incidem sobre a figura do cangaceiro pensando a influência dos repertórios estrangeiros na construção do tecido cinematográfico nacional.

\section{A invenção de Bacurau}

O filme de Juliano Dornelles e Kleber Mendonça' se abre aos olhos do espectador com a imagem do espaço: escuridão imensa, estrelas. O letreiro com o título da obra é apresentado e a câmera começa a se deslocar em torno do seu próprio eixo para a esquerda, momento em que nos deparamos com a imagem do planeta terra. Nesse instante, uma espécie de satélite atravessa a tela, o que já sugere certo movimento de invasão da eletrônica ou elemento moderno na constituição da trama. Tal leitura se sustenta, inclusive, na música que acompanha toda a sequência: na voz de Gal Costa, são entoados os versos de Não identificado, composição de Caetano Veloso. "Disco voador", "espaço sideral" e "objeto não identificado" compõem parte do campo semântico da canção, em oposição a palavras e expressões como "canção singela", "romântico" e "carnaval". Há um ponto de contato entre esses universos de significado quando Gal canta "Eu vou fazer uma canção de amor / para gravar num disco voador". Aí o sentimento de singelo romantismo adentra a esfera ultramoderna, estranha e estrangeira do disco voador. É, portanto, a partir desse conflito expresso na letra de Caetano que a narrativa fílmica se desenvolverá, como veremos adiante.

A câmera como que penetra a terra. A imagem esmaece e defrontamo-nos com a figura de um caminhão-pipa percorrendo uma estrada esburacada de uma região interiorana. A indicação é a de que o terreno fica a Oeste de Pernambuco e em espectro temporal futuro. As informações são registradas emletreiros que aparecem na tela.Dentro do automóvel, os primeiros personagens são apresentados: Erivaldo, motorista do caminhão, e Teresa, que veste um jaleco utilizado por médicos e enfermeiros. Os dois personagens são alarmados por caixões no meio da estrada, fruto do tombamento de um caminhão que os carregava. A câmera revela o caminhão tombado, um agrupamento de pessoas e um homem morto no meio da rua. 
Erivaldo e Teresa seguem o caminho a que tinham se destinado, passam pelas ruínas da escola municipal Silvino Adonias Bezerra, quando são informados pela tela central do automóvel da procura de Adailton do Nascimento (ou Lunga, como é conhecido pelos habitantes de Bacurau) pelas forças do sul.

São prenunciadas algumas situações nas cenas descritas até aqui. Os acontecimentos projetados pela máquina cinematográfica constituem signos, isto é, representações de algo que serão acessadas pelo espectador. A localização geográfica do ambiente, por exemplo, nos sugere a indicação do tipo ou gênero cinematográfico explorado no filme. Os westerns possuem como característica fundamental narrativas de conflito, de dominação de um território ou povo sobre o outro, normalmente ambientados no Oeste dos Estados Unidos.

O western, como ficção literária e gênero do cinema, construiu um imaginário que transfigura uma experiência histórica em termos de uma épica que trabalha a conquista territorial como um eixo central da formação dos Estados Unidos (XAVIER, 2014, p. 171).

Outras representações importantes são mostradas: a morte, as ruínas da educação, o período distópico. Além disso, há o jogo de oposições entre forças do Sul e forças do Norte ligado à figura clandestina de Lunga, espécie de neocangaceiro que se encontra foragido - eis outro elemento deste cinema.

O traço definidor do gênero é o conflito elementar entre civilização e selvageria. Esse conflito básico é expresso através de uma variedade de oposições: Leste contra Oeste, cidade contra sertão, ordem social contra anarquia, indivíduo contra comunidade, inocência contra corrupção, pioneiro contra índio, professora rural contra dançarina de saloon, e assim por diante. A trajetória narrativa de todo e qualquer western aciona a oposição dominante civilização-selvageria, gerando um conflito - ou uma série de conflitos que são constantemente intensificados até que o confronto climácico se torna inevitável (MATTOS, 2004, p. 17-18).

No caso brasileiro, a estrutura do western é revestida pelas cores locais do cenário nordestino ${ }^{2}$ - normalmente plugadas em imagens de devastação ou de precariedade, não raro constituintes do sertão arcaico flagelado pela seca e pela fome. De contornos narrativos semelhantes ao gênero estadunidense, o nordestern do crítico de cinema potiguar Salvyano Cavalcanti tem na figura do cangaceiro a representação do cowboy ou do pistoleiro estadunidense. "A violência, o cavalo, os grandes descampados e a falta de tradição cinematográfica no Brasil: mais nada era preciso para transformar em filial do western norte-americano o filme de cangaceiro, que Salvyani Cavalcanti de Paiva chama de nordestern" (BERNARDET, 2007, p. 60).

O neologismo criado por Paiva assenta em um território este tipo de cinema, em que as disposições antagônicas se estabelecem e se relacionam a partir de sequências de confrontos. Nesse sentido, faz-se necessário pensar em como esses embates são captados em termos de construção imagética-discursiva da região onde se gesta o gênero: o Nordeste. Varjão (2018) estudou a mitologia do Nordeste sob prisma da literatura e do cinema e apontou certo "modelo obsessivo de representação do nordeste", amparado sobretudo na violência e na religiosidade, o que extrapola os extratos ficcionais e são reproduzidos nos setores diversos da sociedade.

O turismo, por exemplo, até hoje ainda lucra com passeios que retratam as trilhas do cangaço, ou com pôsteres e cartões com suas imagens que são vendidos a preços módicos, artistas e escultores dão vida à memória em suas obras. A criação das obras de arte está atrelada fortemente às imagens que se têm da região (VARJÃO, 2018, p. 522).

Bacurau se instaura, ou melhor, é inventado nesse território maniqueísta de oposições: bem versus mal, nativo 
versus invasor estrangeiro. Dessa água bebem alguns outros diretores quando da retratação do cangaço na história do cinema brasileiro, como Lima Barreto este, para Vieira (2007), legitima em seu O cangaceiro (1953) o nordestern no contexto cinematográfico do país, tendo em vista as dinâmicas próprias no campo fílmico (que se tornarão características formais e narrativas comuns a este gênero) - e João Batista de Andrade em O homem que virou suco (1981), por exemplo. Deus e o Diabo na terra do sol (1964), expressivo filme de Glauber Rocha, expõe em seu título a dimensão desse panorama de antagonismos. “Glauber, em 1964, projeta sobre o cangaço as virtudes do bandido social que será motivo do livro de Hobsbawm ${ }^{3}$ em 1968, dentro da mesma perspectiva: ou seja, ele é um protorevolucionário, guerrilheiro" (XAVIER, 2006, p. 59). O imaginário do cangaço em Glauber e nos filmes do Cinema Novo têm no mito da revolução o ensejo comum, de modo que a violência, o despautério do sangue jorrado pelo sertão e a imagem de homens empunhando carabinas ou fuzis são recorrentes. Movidos por interesses afins - quer dizer: o anseio por mudanças de paradigmas sociais e políticos -, a figura do cineasta passa por um processo de isomorfia com relação ao cangaceiro da ficção. O cineasta aponta metaforicamente para o universo cinematográfico a mesma arma (neste caso, a câmera) que o bandido social empunha para se libertar do braço repressivo dos aparelhos do Estado.

No confronto contra a violência maior isto é, a fome, a miséria, a colonização os cinemanovistas justificam a barbárie justiceira de seus personagens. A estética da fome do diretor de $O$ dragão da maldade contra o santo guerreiro (1969) versa sobre uma estética da violência como "o ponto inicial para que o colonizador compreenda a existência do colonizado: somente conscientizando sua possibilidade única, a violência, o colonizador pode compreender, pelo horror, a força da cultura que ele explora"
(ROCHA, 1965).

Esse modelo delimitou o universo imagético dos filmes do Cinema Novo, movimento que representou o modernismo na sétima arte produzida em terras brasileiras a partir da interação entre as imagens urgentes da miséria, da pobreza e o inovador trato com a linguagem fílmica (que incide na apropriação criativa da precariedade dos aparatos técnicos, inclusive, de modo que o procedimento-clichê e marca do movimento é a câmera na mão), além da oxigenação dos aspectos teóricos envolvendo o cinema no contexto dos anos sessenta.

Por outro lado, as terras que assentaram o filme de Kleber Mendonça e Juliano Dornelles são outras. O Brasil e o cinema produzido no século XXI apresentam outras demandas, problemas e implicações. O terreno das utopias brasileiras no campo das artes - o desbunde orgiástico do teatro de José Celso Martinez, o deboche baratinado dos músicos tropicalistas, o mito fundante da formação nacional gerado pelo modernismo, por exemplo - foi fragmentado pelos anos de ditadura. O cinema feito neste século deve, portanto, produzir novas imagens, novas proposições estéticas, novas subjetividades, novos modelos de representação, novos discursos, novas alegorias, sob a suspeita de, não oferecendo enunciados rearticulados ao espectador, ser taxado de anacrônico, pré-moderno. As imagens da barbárie, da violência desmedida e da pobreza associadas aos imaginários da revolução compõem uma poética do tempo passado. Investigando as diferenças de referenciais concernentes à violência geradas pelo nosso cinema no transcorrer do tempo, o crítico Ismail Xavier comenta as características contemporâneas dessas representações.

correlato ao eclipse do bandido social, é também o eclipse da figura do cineasta revolucionário com mandato conferido pela nação. As metáforas dos anos 60-

70 que transformavam a câmera num 
fuzil, o cineasta de esquerda num protoguerrilheiro enfrentando a mídia, e associava a estética da violência às guerras de libertação nacional. A ênfase agora muda e entra em cena um cinema cujos desdobramentos são mais problemáticos, pois este instrumento moderno pode corroer relações e tem consequências imprevistas. Menos ambicioso, o novo cinema reivindica seu espaço na sociedade como um foco de advertência diante da barbárie (XAVIER, 2006, p. 66-67).

A questão do contemporâneo é também problematizada pelo professor e crítico literário Silviano Santiago em artigo sobre a atualidade do inventivo romance de Guimarães Rosa, Grande sertão: veredas. Em face disso, Santiago (2020) discorre com agudez e sensibilidade acerca do atraso de certas manifestações ditas modernas. Para ele, ações como a construção no estilo belle époque da Avenida Central no Rio de Janeiro e o soerguimento da capital federal em plano modernizador, por exemplo, concorreram paralelamente com o crescimento das favelas na cidade carioca e, em Brasília, na desfaçatez desmemoriada no trato com a região do Alto São Francisco, território dominado pela anarquia feroz dos jagunços.

Esses desmembramentos sociais são revelados nas telonas e adquirem os tons deflagrados por tal ou qual repertório acessado pelo cineasta por meio de paronomásias visuais, paródias, metonímias etc. As mudanças de paradigmas éticos e estéticos das produções contemporâneas com relação a cinemas de outros períodos históricos e/ou movimentos artísticos dependem das leituras que os novos diretores fazem de contextos como esse explicitado pelo crítico literário e das escolhas que se valem em se tratando do acervo imagético e discursivo da trama, atrelando-a aos procedimentos de linguagem que modelarão a experiência fílmica.

Pensando esses desdobramentos, o professor dialoga, ainda, com as ideias do filósofo italiano Giorgio Agamben para formular a sua leitura acerca do registro temporal das manifestações artísticas contemporâneas.

Ao afirmar que o contemporâneo é o inatual, Giorgio Agamben se descola das luzes do presente em que vive para receber o escuro da realidade em que vivemos todos. O artista contemporâneo neutraliza o clarão sedutor que norteia o artista na época moderna, para enxergar as trevas, de que as luzes são inseparáveis. Só é contemporâneo quem recebe no rosto o facho de trevas - e não o clarão - que provém do seu tempo. Recebe o facho de trevas no rosto e, no entanto, enxerga (SANTIAGO, 2020).

O contemporâneo é ilustrado como a figuração da sombria opacidade, em detrimento da iluminada transparência realista. Quer dizer, é o artista que carrega em si a poética da elipse, da sugestão, do não-dito, da recusa, enfim; é o que, em lucidez epifânica, busca nas outras tradições maneiras de recriá-las criativamente, e não apenas copiá-las, criando jogos intertextuais de complexas tonalidades; é o que projeta todo o universo em uma única imagem, atestando as facetas várias de sua dicção; é, pois, aquele capaz de suspender o tempo presente para viajar por outras temporalidades e territorialidades. Em Bacurau, na leitura proposta neste trabalho, Dornelles e Mendonça tropeçam em algumas dessas características.

Os dados estão lançados; vamos aos casos e acasos desse singelo interior Não identificado.

\section{Um punhal na mão e uma ideia na} cabeça

Pois bem, o novelo narrativo de Bacurau volta a se desenvolver. A câmera tabela numa sequência fragmentária de planos médios e abertos, enquanto Erivaldo mostra a Teresa as circunstâncias em que se encontram: a barragem que fornece água para o pequeno vilarejo encontrase obstruída por forças desconhecidas. A presença de Lunga é pontuada 
como símbolo de desestabilização dos malfeitores, postoquefoi personagem de uma tentativa (fracassada) de reabilitar o canal. Interessante pontuar os dilemas instaurados pela sintaxe cinematográfica nessa sequência: num momento de introdução das problemáticas que permearão o filme, os supostos inimigos são filmados à distância, são seres sem identidade ou identificação sumária, quer dizer, os representantes do mal são qualquer coisa como estrangeiros, desconhecidos. Os benfeitores são apresentados de perto, tem seus corpos e rostos flagrados de maneira nítida.

Teresa é recepcionada primeiramente pelo pacato Damiano em Bacurau, que Ihe oferece uma estranha substância, talvez uma droga natural. Ela carrega uma mala que contém medicamentos para os moradores do lugar. O cenário é fúnebre: os habitantes do vilarejo estão prestes a enterrar Carmelita, figura bem conhecida naquela constelação social. O velório ocorre sob o som de Bichos da noite, composição de Sérgio Ricardo. A sequência se encerra com a montagem trucada de imagens intercaladas do rosto de Teresa em plano fechado com feições de preocupação, o caixão de Carmelita escorrendo água - símbolo da morte em analogia com o elemento água -, plano fechadíssimo na boca de Teresa engolindo a substância oferecida por Damiano, câmera em plongée sobre a população presente no enterro e, marcado pelo término da música, ocorre a repetição dos dois primeiros movimentos: rosto de Teresacaixão-rosto de Teresa. A câmera em plano aberto filma à distância o último momento do velório: os participantes erguem os braços e balançam ao vento panos brancos, marcando um pedido de paz aos seus algozes.

Outros desenhos próprios do western atravessam a tela, como imagens demarcadoras do território em que se passa a trama. O alaranjado do final da tarde e o fim de luz por detrás das árvores que rodeiam Bacurau anunciam, em quadros posteriores, uma das personas fundamentais do conflito narrativo: a Escola Municipal professor João Carpinteiro - revelando um intertexto paródico com o nome do diretor de Halloween (1978), o cineasta novaiorquino John Carpenter, autor de filmes que vão do terror e da ficção científica a releituras dos westerns clássicos. Bebendo da fonte de Carpenter, o filme aqui analisado também se vale de releituras. Isso fica flagrante quando pensamos a sequência em que Plínio, afável professor, tenta responder ao questionamento postulado por um de seus alunos: "qual éa distância de Bacurau pra São Paulo?", indaga a criança. O excerto fílmico, parece-nos, é um remodelamento de uma das cenas iniciais de $O$ dragão da maldade, supracitado filme de Glauber Rocha. Os fotogramas a seguir indicam as semelhanças, tanto no que se refere ao enquadramento como na disposição dos personagens.

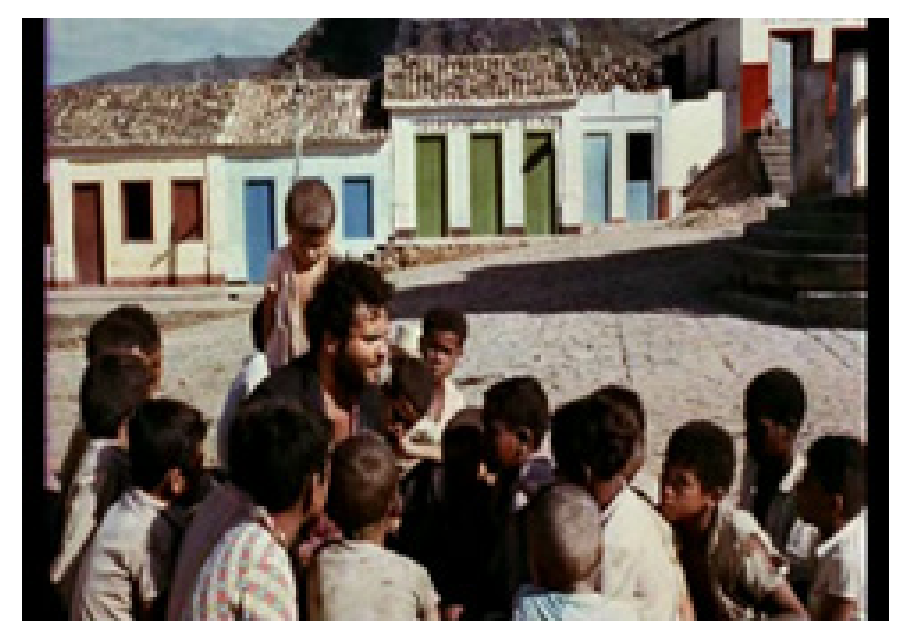

Figura 1: o professor e as crianças. Frame do filme "O dragão da maldade contra o santo guerreiro", 1969.

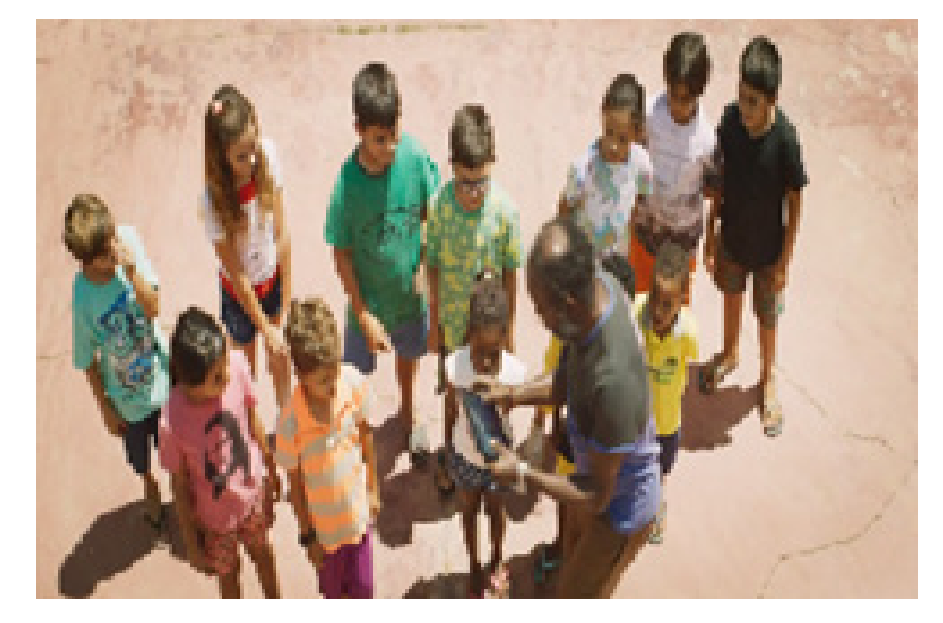

Figura 2: crianças, professor e tablet. Frame do filme "Bacurau", 2019. 
No filme do diretor baiano (Figura 1), os alunos, cercando o professor, respondem mecanicamente a proposições postuladas por ele acerca de eventos e figuras históricas correspondentes à construção da identidade nacional. São perguntadas as datas de descobrimento do Brasil, da independência, da abolição da escravidão, da proclamação da república e, ao fim, da morte de lampião. Essa interação cenográfica nos sugere a leitura crítica por parte do cineasta dos modelos pedagógicos que assumiam o conhecimento como uma moeda de troca a serviço da máquina capitalista. Nessa arcaica metodologia, os alunos assumem acriticamente as informações propostas pelo professor e cabe a eles apenas decorar datas. Em Bacurau (Figura 2), o panorama se modifica, dado que de cara o espectador é confrontado por elementos modernizantes. Quem profere as perguntas são os alunos, - que causa um deslocamento nas relações de poder instauradas pelo paradigma professor-aluno. Além disso,
Plínio porta um tablet que o auxilia, pontuando a intrusão da eletrônica no processo pedagógico. Na sequência posterior, instigado pela dúvida acerca da localização de Bacurau no mapa, o professor entra com a turma na sala de aula e procura a pequena cidade no mapa digital, que está projetado numa televisão. Não obtendo sucesso, ele desiste da tecnologia e apresenta aos alunos um mapa desenhado à mão onde Bacurau está situado. Dialogam no filme dos cineastas pernambucanos, portanto, o arcaico e o moderno, o digital e o analógico, criando uma dimensão temporal difusa, apesar da expressa indicação de tempo futuro.

“Pessoal, Tony Júnior na área, hein? Repetindo: Tony Júnior na área!", comunica Darlene (uma espécie de informante) por celular da entrada do prefeito na cidade. Quando do recebimento do recado pelo carro de som de DJ Urso (músico local), os habitantes de Bacurau complacentemente abdicam de seus afazeres para se recolherem em suas casas, em demonstração de resistência à força política que está se aproximando. A constituição dos afetos entre os moradores nos permite apontar novamente a difusa temporalidade expressa no ambiente. Essa vida comunitária enseja os estereotipados enunciados postulados pela indústria cultural e por parte dos discursos da política institucional sobre o interior nordestino, como aponta o historiador Durval Muniz em artigo sobre o filme: "A anacrônica nostalgia da vida comunitária, da vida da cidade pequena, dos sertões, um certo pastoralismo nostálgico, tão característico das esquerdas dos anos sessenta, aí se faz presente" (MUNIZ, 2019).

Após chegar em Bacurau acompanhado de um caminhão carregando livros em estado de condições precários - que são despejados na frente da escola João Carpinteiro -, Tony Júnior, enquadrado em plano americano, anuncia num megafone as motivações de sua visita: o aproximado período de eleições. Além dos livros velhos, ele deixa aos habitantes alimentos, caixões e medicamentos de tarja preta que inibem o humor. $\mathrm{Na}$ saída, o prefeito leva a prostituta Sandra em seu carro, visivelmente contrariada. Instaura-se aí o cenário já conhecido do coronelismo, representação constante na invenção do nordeste pelas manifestações culturais regionalistas.

Os discursos regionalistas surgem na segunda metade do século XIX, à medida que se dava a construção da nação e que a centralização política do Império ia conseguindo se impor sobre a dispersão anterior. Quando a ideia de pátria se impõe, há uma enorme reação que parte de diferentes pontos do país. Este regionalismo se caracterizava, no entanto, pelo seu apego a questões provincianas ou locais, já trazendo a semente do separatismo. [...] A escolha de elementos como o cangaço, o messianismo, o coronelismo, para temas definidores do Nordeste, se faz em meio a uma multiplicidade de outros fatos, que, no entanto, não são iluminados como matérias capazes de dar uma cara à região. 
A escolha, porém, não é aleatória. Ela é celular; posteriormente, encostados em dirigida pelos interesses em jogo, tanto no interior da região que se forma, como na sua relação com outras regiões (MUNIZ, 2011, p. 60-61).

Nas cenas que decorrem, os elementos configuradores do conflito-ápice da narrativa surgem com mais intensidade. O drone em formato de disco voador sobrevoando Damiano enquanto ele percorre uma estrada de terra numa motocicleta, a estranha migração dos cavalos que habitavam uma fazenda próxima ao povoado - em decorrência de um ataque sofrido pelo lugar -, buracos de bala cravados na lataria do caminhão-pipa de Erivaldo e a presença inesperada de um casal de motoqueiros são indicadores do confronto que está sendo estabelecido. Os motociclistas forasteiros, representantes alegóricos do Sul do Brasil, interagem com os moradores em dois ambientes: em um bar, primeiramente, onde instalam debaixo de uma bancada um mecanismo eletrônico capaz de cortar o sinal de suas motos, na rua. Nos dois momentos, há a sugestão de visita do museu histórico de Bacurau, indicação não acatada pelo casal.

O museu, instituição responsável pela conservação do patrimônio histórico, é alçado como carta de boas-vindas aos visitantes do lugar. Antes de ser essa instituição de manutenção de armas, documentos, obras de arte e outros elementos que detêm relevância para a construção do passado histórico, o museu mais nos parece uma metáfora para representar Bacurau - cidademuseu, relegada a uma invenção subjetiva norteada por imagens e discursos ultrapassados, sobretudo quando tratamos desses signos (pastoralismo, coronelismo, escassez, etc.) no imaginário cultural brasileiro. Dornelles e Mendonça tentam uma distopia, mas acabam criando uma experiência fílmica enterrada no pior passado constituído para o nordeste. Os acontecimentos que sucedem a trama atestam essa afirmação.

A matança desenfreada fará parte do enredo. O casal, no caminho para a fazenda de onde escaparam os cavalos, esbarra com dois locais que vinham de lá e tinham avistado um carro destronado, uma casa com a porta escancarada e várias pessoas mortas. A câmera acompanha o diálogo do encontro em jogo de plano e contraplano, traçando em linguagem cinematográfica a oposição entre as partes. Os sulistas descem de suas motos, perguntam se os homens estão com celular e se o sinal do aparelho está funcionando. Eles, assustados, respondem que sim que estão com celular e com sinal -, ao passo que são surpreendidos por armas empunhadas pelo casal. Os dois homens são assassinados. O drone disfarçado de disco voador filma toda a ação de cima, lugar de onde os portadores do aparelho se colocam hierarquicamente, por possuírem ascendência europeia e norte-americana. O casal vai de encontro a esses estrangeiros, localizados na denominada "base", uma casa colonial, identificada como tal por fotografias alocadas na parede.

Na chegada dos sulistas, organiza-se uma reunião na mesa de refeições da casa. Na cena inicial da conversa, a câmera descortina num plano de conjunto os vilões da história, personagens alegóricos que representam as forças colonizadoras: homens e mulheres de cor branca, naturais da Europa, dos Estados Unidos e, aliados a eles, o casal do Sul do Brasil. A colonização, figuração do passado das terras brasileiras, mas que se perpetua em nosso presente, é tensionada na caracterização dos capangas, que utilizam apenas armas vintage em suas ações, isto é, elementos datados que são estetizados para o tempo presente.

O espectador descobre nesse momento os responsáveis pelo ataque na fazenda, dois dos integrantes do grupo, Jake e Terry. A câmera passa pelo rosto dos dois e depois mira o perfil do alemão Michael, líder do bando, ao que parece. 
Na reunião, os integrantes discorrem sobre a futura invasão que farão no povoado de Bacurau, sem que as motivações fiquem claras. O único ensejo apresentado a quem assiste ao filme são os comandos estabelecidos por uma voz que fala com os estrangeiros por meio de comunicadores eletrônicos que eles portam (os brasileiros não possuem esse equipamento). A voz indica as informações de como os ataques devem acontecer, quem deve morrer e o número de munição que pode ser utilizado na ação. A dinâmica se assemelha a de um jogo de videogame e essa leitura se potencializa quando descobrimos que cada morte equivale ao ganho de determinado número de pontos pelo assassino. A sequência da reunião finda com a execução dos brasileiros pelo descumprimento das regras estabelecidas pelos estrangeiros, sendo elas a utilização de armas modernas e a intrusão na captação de pontos em decorrência do confronto com os nativos na estrada da fazenda.
Acácio (também conhecido pelo apelido de Pacote) - matador de aluguel nas cidades grandes, signo do ressentimento no imaginário dos flagelados gestado por arcaizantes manifestações culturais brasileiras, corroborando, como já citamos, o panorama museológico das representações que compõem Bacurau defronta-se com o horror provocado pela facção de Michael na estrada. Ele recolhe os cadáveres estendidos na rua de terra e, após breve diálogo com Damiano, afirma que vai atrás de Lunga. A câmera pousa sobre ossos de um animal no chão; a imagem esmaece e se reestabelece mostrando uma cruz velando o defunto de alguém que fora enterrado debaixo daquele terreno. $\mathrm{O}$ acervo estético por vezes anacrônico que incide sobre o filme dá o tom mais uma vez nessa sequência, rodada em parte sob o som de Réquiem para matraga (composição de Geraldo Vandré, música-hino da arte engajada em oposição à ditadura militar). Os versos da canção fazem as vezes da cruz, acompanhando as imagens-cadáveres num desvelamento que aponta para a barbárie sem precedentes.

Lunga encontra-se foragido na barragem que represava a água que abastecia Bacurau, antes de ser obstruída pelos inimigos. Composto por interessante identidade visual - em devir, na fronteira entre o feminino e o masculino -, o personagem é uma revisão da imagem do cangaceiro. Apesar dos traços modernos, Lunga carrega, como se verá, a mesma marca de ressentimento que se expressa em Acácio, o que se afigura, então, é antes uma exótica identidade pré-moderna do que pós-moderna do cangaço.

Pacote rapidamente convence Lunga da necessidade em tê-lo na pequena cidade para combater os ataques estrangeiros. Sua chegada é celebrada pelos habitantes. A escuridão da noite invade as ruas de Bacurau, o que se vê são velas acesas pelos que partiram. A população, em roda, dança capoeira, manifestação da resistência de povos escravizados no período de colonização.
Estamos nesse momento diante de outro elemento de museu: o imaginário da resistência revolucionária a partir da coesão absoluta de um grupo, sob a tutela ou chefia de um predestinado messiânico, normalmente injustiçado, vindo de outras cercanias, lugar-comum de tantas narrativas sobre o sertão nordestino - de Canudos ao bando de lampião a letra é a mesma.

O recém-chegado comanda, com uma pá em punho, a abertura de um buraco no solo, ao que os residentes auxiliam prontamente. As mortes, no entanto, não cessam. Nessa mesma noite, uma criança é assassinada por um dos tiras norte-americanos. Câmera em plano fechado diante da face de Lunga. Com os olhos esbugalhados de tensão, ele profere: "a gente tá sendo atacado!". Claudio e sua mulher, residentes nativos, sob o peso do desespero, tentam fugir de carro do lugar, ao que são metralhados pelos invasores.

No dia seguinte, dois dos estrangeiros se dirigem furtivamente para a casa de 
Damiano. Enquanto rega as suas plantas, resto do grupo mira o centro de Bacurau. ele percebe a presença estranha, o que Ele esbarra em Domingas (médica o conduz ao preparo de pólvora para local), que posa a sua frente com uma abastecer as armas que têm em sua casa. As cenas que seguem são, por parte do público que assiste, animadoras, cativantes, dado que o jogo da história começa a mudar, isto é, o bem inicia o seu processo de dominação ou, melhor dizendo, de reação sobre o mal: os dois invasores são fuzilados pelas armas de Damiano e de sua esposa, Daisy. Problematizemos esse processo de reação.

O filme se encaminha para o seu período final com o clássico cenário de bang-bang envolvendo as forças da província versus os braços pesados do terror estrangeiro. A câmera em plano de detalhe na boca dos habitantes de Bacurau ingerindo o que denominamos furtivamente de "droga natural", conotando uma preparação para o confronto, demonstra um componente importante no conflito.

O bando dos invasores se divide. Michael segue sozinho, enquanto o da cidade, quando são surpreendidos por mais uma personagem metafórica da trama, a escola João Carpinteiro, lugar de onde provém os tiros da salvação de Bacurau. É como se, no seio da escola e dos estudos, residisse o alimento da resistência de um povo. A pedagogia impressa pelos oprimidos, entretanto, parece-nos tão cruel e impiedosa quanto a violência exercida pelos opressores, atestando não o poder restaurador, reflexivo e conscientizador da educação, mas a sua capacidade de reprodução dos valores instituídos.

É dos porões da história, ainda, que se encontram outros elementos que nos permitem elaborar tal afirmação. A pedagogia da violência destitui os seres humanos dos valores fundamentais, de modo que o vencedor da história é expresso sempre sob a égide da barbárie, isto é, ganha quem mata mais. O cangaço, por exemplo, legitima-se no discurso escuso da reação violenta contra os seus detratores. Em Bacurau não é diferente, Lunga literalmente aparece dos porões do museu para o derramamento de sangue final do filme. Com a câmera fechada em seu rosto, vemos o neocangaceiro golpear com um punhal o pescoço do inimigo, cortando a sua cabeça.

Na cena posterior, a finada Carmelita aparece como uma entidade espiritual que reside sobre a cidade. A última sequência apresenta os moradores carregando caixões de pessoas como Marisa Letícia Silveira da Costa e Marielle Gomes de Sousa - referências transversais a ex-esposa do presidente Luiz Inácio Lula da Silva, Marisa Letícia, e a ex-vereadora do Rio de Janeiro, Marielle Franco, que tiveram as suas mortes e, sobretudo, as suas memórias rechaçadas pelos setores mais conservadores e reacionários da sociedade brasileira. Estes, que são frutos exatamente dessa dizibilidade e visibilidade da violência, pedras de onde tiram os seus projetos de poder.

A câmera flagra em plano de conjunto a infeliz e tão brasileira imagem das 
cabeças cortadas, expostas em praça pública para deleite dos presentes. 0 encerramento se dá com o encontro de Michael e do prefeito Tony Júnior, apresentados como aliados. A "droga natural" - pulsão energética corporal que habilitou, talvez, os moradores de Bacurau ao conflito que se desembocou - é descrita por Plínio como um poderoso psicotrópico. A morte de Tony Júnior é anunciada e Michael é levado para o buraco que havia sido cavado por Lunga e seus ajudantes. Ao ser enterrado, o alemão profere a frase "isso é só o começo". Isto é, para um regime calcado na crueldade, o horizonte de saída não se encontra em um referente próximo.

A sequência termina com a celebração da barbárie gerada pela interação entre a partitura visual e a partitura sonora do filme, como afirma o diretor e montador cinematográfico Eduardo Escorel nas linhas que seguem.

Após ter começado com Não identificado, a "canção singela, brasileira" de Caetano Veloso, Bacurau termina com Réquiem para matraga, na voz de seu autor, Geraldo Vandré: "vim aqui só pra dizer / Ninguém há de me calar / Se alguém tem que morrer / Que seja pra melhorar [...]". Como devemos entender esses versos entoados de modos a parecer palavra de ordem? Seriam uma forma de Mendonça Filho e Dornelles justificarem seus personagens por fazer justiça com as próprias mãos? Além de desafiar qualquer tentativa de emudecer quem canta (ou filma), a canção e o filme pretendem defender o ato de matar desde "seja para melhorar?" (ESCOREL, 2019).

A tela escurece. Os créditos sobrepõem a escuridão que se projeta.

\section{Conclusão (ou: a projeção se encerra)}

Ambientado pelos acervos culturais produzidos pelas artes brasileiras e estrangeiras e o pensamento teórico engendrado por tais (especialmente no que se refere ao cinema), este trabalho buscou consultar alguns enunciados gerados por esses repertórios para mapear historicamentea ética ea estética de Bacurau no contexto do cinema brasileiro. Recorremos, portanto, para além dos artigos, teses e dissertações sobre cinema, à história e à sociologia, a fim de assegurar uma leitura crítica que integrasse a análise da violência na arte e na sociedade.

Trocandofigurinhascomessasreferências científicas, este texto alia a elaboração artística - e as suas implicações próprias no campo da linguagem (no caso do filme analisado, detivemo-nos ao estudo de enquadramentos, movimentos de câmera e elementos de cena, por exemplo)-aopensamentogestadosobre a recepção crítica da obra, atestando, por meio de investigações comparativas, a ainda presente preponderância de relações coloniais arcaizantes tanto na tessitura do filme examinado, como no tecido social brasileiro de maneira geral. Percebemos, então, que o filme estudado concentra alguns discursos e imagens balizados na estereotipia, representantes da construção histórica, política e social de uma região. Esta crítica, sob ponto de vista ético, admite, portanto, a contundente recusa em considerar o fenômeno artístico apenas a partir de um ponto de vista, quer dizer, a interface filme/resistência, dualidade questionada e desconsiderada neste texto pelos elementos devidamente elencados e analisados. A obra de arte, para ser considerada como tal, precisa necessariamente ser diversa, múltipla, aberta a um sem número de leituras e interpretações. Do contrário, penaríamos sobre um fenômeno tutelado sob palavras de ordem e/ou chavões reacionários.

Desse modo, acreditamos que este trabalho é sobretudo uma ode ao movimento gerado pelo pensamento que se estabelece a partir da dissidência, do democrático conflito de ideias e apontamentos motivado pela pluralidade de leituras e olhares acerca de um fenômeno em comum: a obra de arte. Ainda assim, toda a nossa discussão crítica a respeito do filme de Kleber Mendonça e Juliano Dornelles reflete, 
conceitual, a profunda intimidade afetiva com o objeto de estudo, o filme, e é só em relação a ele que os posicionamentos aqui expostos se fundamentam.
1 Os realizadores se situam no contexto do novo cinema pernambucano, índice da chamada "pós-retomada". Em O cinema contemporâneo de Pernambuco, Santos (2019) cataloga-os e aponta algumas "Estruturas de sentimentos" ligadas ao grupo, tais quais: "experimentação narrativa que desloca paradigmas clássicos do que seja documentário e ficção, muitas vezes, confundindo as fronteiras entre um e outro e questionando mesmo uma classificação possível. [...] Outra herança moderna que podemos perceber em alguns filmes dessa geração é o recurso à alegoria (de allo, outro e agorein, dizer), ou seja, dizer algo de sentido distinto do literal. O uso de argumentos narrativos metafóricos, montagem descontínua ou fragmentada, arranjos improváveis de cenários, signos díspares que são reconfigurados, associações conotativas entre símbolos e/ou objetos pertencentes a universos de sentidos usualmente distintos, são alguns recursos que reiteram esse desígnio". Outros elementos caros a esta geração estão explícitos no trabalho de Silva (2015) intitulado O SOM AO REDOR DO BAILE: Retomada e pós-Retomada no cinema produzido em Pernambuco, quais sejam: a cinefilia e a "brodagem".

${ }^{2}$ Vieira (2007) afirma que as primeiras manifestações de ficcionalização do cangaço pelo cinema datam dos anos 1920, mas essas experiências só se solidificaram como gênero quando o western já estava difundido e conhecido ao redor do mundo.

${ }^{3}$ Trata-se do livro do historiador britânico Eric Hobsbawm: Bandidos.

HOBSBAWM, Eric. Bandidos. Tradução Donaldson M. Garschagen. 4. ed. São Paulo: Paz e Terra, 2015. 198 p. 


\section{REFERÊNCIAS BIBLIOGRÁFICAS}

BERNARDET, Jean-Claude. Brasil em tempo de cinema: ensaio sobre o cinema brasileiro de 1958 a 1966. São Paulo: Companhia das letras, 2007.

ESCOREL, Eduardo. Bacurau - celebração da barbárie. Piauí. Disponível em: $<$ https://piaui.folha.uol.com.br/bacurau-celebracao-da-barbarie/>. Acesso em: maio. 2020.

GOMES, Paulo Emílio Sales. Uma situação colonial?. 1 ed. São Paulo: Companhia das letras, 2016.

MATTOS, Antônio Carlos Gomes de. Publique-se a lenda: a história do western. 1 ed. Rio de Janeiro: Rocco, 2004.

MUNIZ, Durval. A invenção do nordeste e outras artes. 5 ed. São Paulo: Cortez, 2011.

. Bacurau: será mesmo resistência?. Saiba Mais. Disponível em: $<$ https://www.saibamais.jor.br/bacurau-sera-mesmo-resistencia/>. Acesso em: abril. 2020.

ROCHA, Glauber. Eztetyka da fome.
Hambre espacio cine experimental. Disponível em: <https://hambrecine. com/2013/09/15/eztetyka-da-fome/>. Acesso em: maio. 2020.

SANTIAGO, Silviano. Grande sertão: crossroads blues. Suplemento Pernambuco. Disponível em: <https://www. suplementopernambuco.com.br/artigos/2505-grande-sert\%C3\%A3o-crossroads-blues.html>. Acesso em: junho. 2020 .

SILVA, Renato Kleibson da. $\mathbf{O}$ som ao redor do baile: retomada e pós-retomada no cinema produzido em Pernambuco.

2015. 130f. Dissertação de Mestrado UFRN, Natal, 2015.

VARJÃO, T. DE B. As mitologias do sertão através do cinema e literatura. Letras de Hoje, v. 53, n. 4, p. 517-525, 30 dez. 2018. VIEIRA, Marcelo Dídimo Souza. 0 cangaço no cinema brasileiro. 2007.418f. Tese de Doutorado - UNICAMP, São Paulo, 2007.

XAVIER, Ismail. Da violência justiceira à violência ressentida. Ilha do desterro, Florianópolis, v. 51, pp. 55-68, Jul./dez. de 2006.

XAVIER, Ismail. John Ford e os heróis da transição no imaginário do western. Novos estudos, São Paulo, v. 100, pp. 171-192, Novembro de 2014.

XAVIER, Ismail. Sertão Mar. 1 ed. São Paulo: Duas cidades; Editora 34, 2019.

\section{REFERÊNCIAS FILMOGRÁFICAS}

BACURAU. Direção: Kleber Mendonça Filho e Juliano Dornelles. Produção de Emilie Lesclaux. Pernambuco: Cinemascópio, sbs, 2019. 1 DVD (132 min.).

DEUS e o diabo na terra do sol. Direção: Glauber Rocha. Rio de Janeiro: Copacabana filmes, 1964. 1 DVD (118 min.).

HALLOWEEN. Direção: John Carpenter. Califórnia: Compass International Pictures, 1978. 1 DVD (112 $\min$.$) .$

O DRAGÃO da maldade contra o santo guerreiro. Direção: Glauber Rocha. Rio de Janeiro: Mapa Filmes, 1969. 1 DVD (95 min.). 